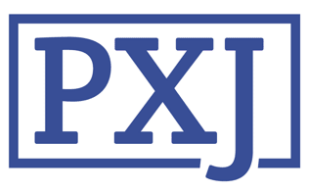

Patient Experience Journal

Volume 8 | Issue 1

Article 10

2021

\title{
Patients' and family caregivers' perceptions of doctor-to-doctor advice and electronic referral notifications in Alberta
}

Yong Li

Alberta Health Services, Calgary

Annabelle Wong

formerly of Alberta Health Services, Calgary

Follow this and additional works at: https://pxjournal.org/journal

Part of the Health and Medical Administration Commons, Health Policy Commons, Health Services Administration Commons, Health Services Research Commons, and the Medical Specialties Commons

\section{Recommended Citation}

Li Y, Wong A. Patients' and family caregivers' perceptions of doctor-to-doctor advice and electronic referral notifications in Alberta. Patient Experience Journal. 2021; 8(1):77-87. doi: 10.35680/

2372-0247.1441.

This Research is brought to you for free and open access by Patient Experience Journal. It has been accepted for inclusion in Patient Experience Journal by an authorized editor of Patient Experience Journal. 


\section{Patients' and family caregivers' perceptions of doctor-to-doctor advice and electronic referral notifications in Alberta}

\section{Cover Page Footnote}

The authors are deeply grateful to all the patients and caregivers who participated in this study. The authors would like to thank all contributors who shared their expertise during the development of the online survey. Their names are listed in alphabetical order: Astrid Hryciuk, Dr. Bettina Lott, Bonnie Lakusta, Dr. Hien Huynh, Karen Moffat, and Sarah Vandusen. The authors would like to thank their colleagues from Alberta Health Services, the Alberta Medical Association, Alberta SPOR SUPPORT Unit (AbSPORU) and Canada Health Infoway for distributing the survey via their communication networks. Last but not least, the authors thank Carrie Newman and Jennifer Colp for their time and enthusiasm for proofreading the manuscript. This article is associated with the Patient, Family \& Community Engagement lens of The Beryl Institute Experience Framework (https://www.theberylinstitute.org/ExperienceFramework). You can access other resources related to this lens including additional PXJ articles here: http://bit.ly/

PX_PtFamComm 


\title{
Patients' and family caregivers' perceptions of doctor-to-doctor advice and electronic referral notifications in Alberta \\ Yong Li, Alberta Health Services, Calgary,yong.li@abs.ca \\ Annabelle Wong, formerly Alberta Health Services, Calgary, awn@ualberta.ca
}

\begin{abstract}
Effective communication between health professionals and patients is essential to patient safety and quality care. Primary care providers seeking specialist advice to manage patients' conditions in the community has recently been adopted to improve timely access to specialty care and increase the efficacy of the referral process. To understand patients' and family caregivers' perceptions on doctor-to-doctor advice for non-urgent clinical questions and electronic referral communications with patients in Alberta, a mixed method online survey was conducted by Alberta Health Services' Access Improvement team. A total of 1,422 patients and family caregivers living in Alberta were included in the quantitative and qualitative analysis. Although the majority of participants were comfortable with their doctors seeking advice via secure online messaging systems (93\%) and over the phone (89\%), about half of the participants did not know if their family doctors had ever obtained advice from a specialist to support their care. Their concerns surrounding doctor-to-doctor, non-urgent advice included the security of transferred information, privacy and confidentiality of patient information, misunderstanding of information, and delayed communication. In addition, $63 \%$ of participants reported that email was the most convenient way to receive electronic notifications about their referrals. Increasing patients' and family caregivers' awareness of advice services in Alberta will help promote person-centered care and improve communication during the referral and consultation process. Our findings also encourage healthcare providers and policymakers to further evaluate key areas for improvement and implement new strategies to promote better patient and provider communications while enhancing timely access to specialty care.
\end{abstract}

\section{Keywords}

Electronic advice, phone advice, referral notifications, specialty referrals

\section{Introduction}

Over the past two decades, the referral and consultation process has become more complex and numerous problems have been identified with rising demands on referrals ${ }^{1,2}$ - long wait times for diagnosis and treatment, ${ }^{3-5}$ communication issues, ${ }^{6-10}$ poorly coordinated referral systems, $7,11,12$ incomplete referral letters, and unclear responsibilities during the referral process. ${ }^{7,13}$ Many interventions have been implemented in an attempt to improve access to specialty care, reduce referral errors or increase monitoring of performance. ${ }^{14}$ However, poor referral experiences such as unclear communication, lost referrals and long wait times were still reported by patients in recent studies. ${ }^{5,6}$

As a result of the increasing wait times from when a referral is made to an initial specialist appointment in Canada, 5,15 many healthcare providers have adopted an innovative strategy to respond - using electronic advice (also known as eConsult or eConsultation). Electronic advice provides a secure communication platform for primary care providers to seek specialist guidance for non- urgent clinical questions. Several jurisdictions have shown that the use of electronic advice reduced the number of patients requiring traditional in-person specialist appointments as well as improving referral clarity. ${ }^{16-18}$ Primary care providers also rated this service as being of high value and that they had more confidence to manage patients' conditions in the community. ${ }^{19,20}$ The results are promising and suggest that the widespread use of electronic advice has the potential for more efficient use of resources. It can improve timely access to specialty care by providing an acceptable alternative for non-urgent patients to receive advice from specialists and continue treatment under the care of their primary care providers. ${ }^{17,21-26}$

The referral-consultation process does not only involve primary care providers, specialists and support staff, but also patients and their caregivers. However, little is known about the perspectives of patients and family caregivers on doctors seeking advice virtually, nor communicating referral updates electronically between patients and healthcare providers. Patients expressed the desire for a person-centered healthcare approach where they are 
engaged in the decision-making process and their preferences and demands are valued. 6,10,27

This paper focuses on studying Alberta patients' and family caregivers' perceptions on primary care providers seeking non-urgent clinical advice virtually and their preferences on receiving referral communications electronically.

\section{Methods}

\section{Study Participants and Design}

All patients who had been referred to see a specialist in Alberta and all family caregivers who provided care for someone being referred to see a specialist in Alberta were eligible to participate in this study.

To assess patients' and caregivers' degree of satisfaction with the referral process and their perspectives on receiving referral and consultation communication electronically, a mixed-method survey was developed by the second author and finalized after a series of consultations with two patient advisors, a primary care physician, a specialist, an evaluation consultant from the Alberta Medical Association, and a policy analyst from Alberta Health. The online survey was built using the software SelectSurvey.NET, which is a secure online survey platform approved by the Alberta Health Services (AHS). See Appendix for a complete list of questionnaires. This paper focuses on the last two sections of survey which included the following three questions:

1) Have participants' family doctors ever obtained advice from specialists for non-urgent clinical questions to support their care? If yes, which methods were used?

2) Would participants be comfortable having their family doctors seek advice from a specialist for non-urgent clinical questions electronically (i.e. secure online messaging) or over the phone (including via text message)? What concerns might they have if they were not comfortable?

3) What information related to a referral would participants like to receive electronically? Which format of electronic messaging would be the most convenient for them?

\section{Data Collection}

This survey was distributed to patients and family caregivers who had signed up for electronic communications (email and/or Twitter) from AHS Patient Engagement, the Alberta Medical Association, the Alberta Strategy for Patient Oriented Research or Canada Health Infoway. Data were collected from the last two sections of the survey administrated by the AHS Access Improvement team between Nov. 1, 2019 and Jan. 2, 2020.

\section{Data Analysis}

Quantitative data were collected and analyzed by SPSS version 25.0. Written comments in the open-ended questions were imported into NVivo12, then reviewed by each author individually to identify patients' and family caregivers' concerns on doctor-to-doctor advice electronically and over the phone. Main themes were categorized at the semantic level using inductive approach and were finalized after agreement was reached between the two authors.

\section{Results}

Of the 1,734 respondents that participated in this survey, five did not provide consent; 225 did not complete the survey questions; 29 did not have referral experience; and 53 did not reside in Alberta. A total of 1,422 Albertans were included in the final analysis. The participants' demographics are summarized in Table 1 . The majority of the participants were patients $(65 \%)$, female $(82 \%), 50-69$ years of age $(58 \%)$, retired $(39 \%)$, and had completed college/undergraduate/graduate degrees (64\%).

In Alberta, primary care providers are allowed to obtain advice from specialists for non-urgent clinical questions over the phone or electronically. However, about half of the participants $(49 \%)$ indicated they did not know if their family doctors had ever obtained advice from a specialist to support their care. Even though 341 participants (24\%) were aware of their family doctors seeking advice from a specialist to manage their care, the majority of them $(62 \%)$ did not know how their family doctors obtained the advice. In addition, 179 out of 341 participants (53\%) mentioned their family doctors did not ask if they had any questions for the specialist at all. Fortunately, most of them $(76 \%)$ indicated that their family doctors shared the specialists' recommendations with them.

In regard to the participants' perspectives on family doctors seeking advice from specialists virtually, the majority of participants reported being comfortable that their family doctors use secure online messaging $(93 \%)$ or communicate over the phone including via text message $(89 \%)$.

Amongst participants who indicated they were not comfortable or not sure about family doctors seeking advice virtually, 98 participants shared their concerns about using electronic advice and 145 participants expressed their concerns about getting advice over the phone. There were a lot of similarities in the written comments for concerns on seeking advice electronically and over the phone. Table 3 summarizes the main themes that emerged in the qualitative analysis. 
Table 1. Demographics of Survey Participants $(n=1,422)$

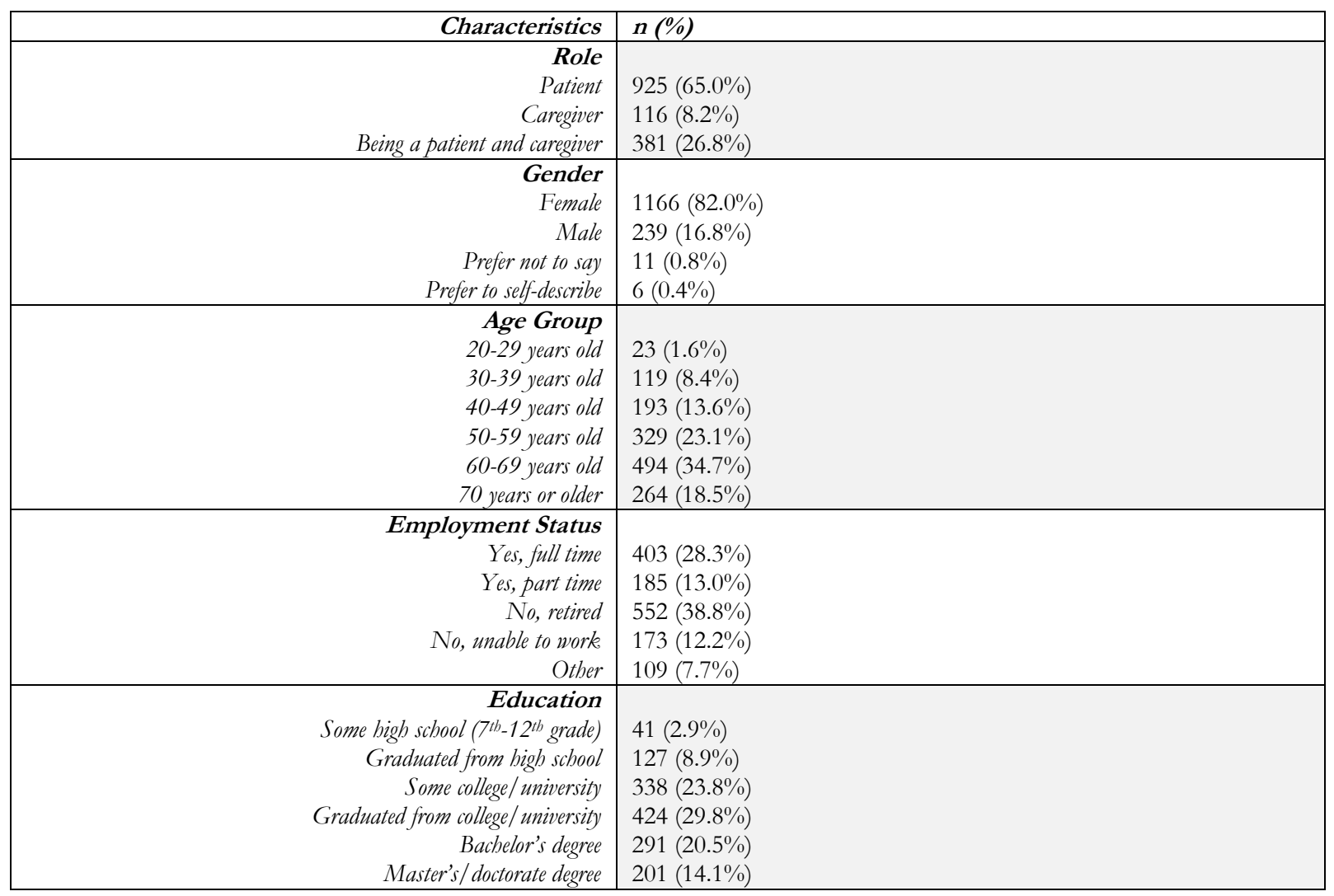

Table 2. Perspectives on Doctor-to-Doctor Advice on Non-Urgent Clinical Issues

\begin{tabular}{|r|r|l|l|}
\hline Would you be comfortable having your family doctor & Yes & No & I don't know \\
\hline Seek advice electronically (i.e., secure online messaging) & $1,317(92.6 \%)$ & $39(2.7 \%)$ & $66(4.6 \%)$ \\
\hline Seek advice over the phone (including via text message) & $1,263(88.8 \%)$ & $77(5.4 \%)$ & $82(5.8 \%)$ \\
\hline
\end{tabular}

Alberta is currently exploring the option of electronic notifications (i.e. secure messaging) to patients and/or their caregivers in order to enhance the referral communication process. An overwhelming number (95\%) of participants indicated they would like to receive information related to their referrals electronically. Information included referral status (93\%), approximate wait time for the first appointment with the specialist (91\%), appointment details $(93 \%)$, reason for referral $(73 \%)$, and request for advice submitted on the patient's behalf $(78 \%)$.

In addition, participants suggested they should be electronically notified about the following information: instructions/guidelines for their conditions, results of their referrals and tests, reasons for being waitlisted or declined, and recommendations from specialists. Participants also used the "free-text" space to emphasize the importance of keeping patients in the loop of all communications. In terms of format of electronic messaging, 901 out of 1,422 participants $(63 \%)$ reported that email would be most convenient for them, followed by an online patient portal (Figure 2).

\section{Discussion}

Shared decision-making not only increases patient, family caregiver and physician satisfaction with a consultation, it also improves patient health outcomes. ${ }^{28}$ Physicians should inform patients whether they want to seek advice from a specialist, provide details of what advice was requested, 
Table 3. Four Themes Emerged from Concerns about Doctors Seeking Advice from Specialists Electronically and/or Over the Phone

\begin{tabular}{|c|c|c|}
\hline Themes & Quotes & $\begin{array}{c}\text { Modality } \\
\text { (Electronic, } \\
\text { Phone or Both) }\end{array}$ \\
\hline $\begin{array}{r}\text { Security of transferred } \\
\text { information }\end{array}$ & $\begin{array}{l}\text { - "Information security, the internet isn't always safe even with } \\
\text { secure lines." }\end{array}$ & Both \\
\hline $\begin{array}{l}\text { Privacy and confidentiality of } \\
\text { patient's information }\end{array}$ & $\begin{array}{l}\text { - "My concern is privacy. With systems being hacked all of the } \\
\text { time I wouldn't want my personal information at risk.". } \\
\text { "The biggest concern would be communication via texting. It is } \\
\text { not secure or private. Phone calls would be ok but cannot be } \\
100 \% \text { sure of accurate transfer of information. The best is by } \\
\text { email/fax to get accurate transfer of information." }\end{array}$ & Both \\
\hline $\begin{array}{r}\text { Misunderstanding in } \\
\text { communication } \\
\end{array}$ & $\begin{array}{l}\text { - "Discussion between doctors can be misunderstood and then } \\
\text { miscommunicated for a variety of reasons." }\end{array}$ & Both \\
\hline $\begin{array}{r}\text { Time demand for communication } \\
\text { electronically }\end{array}$ & $\begin{array}{l}\text { - Would be concerned with assumptions being made because of } \\
\text { time delays in back-and-forth emails. Completely support } \\
\text { phone conversations." }\end{array}$ & Electronic \\
\hline
\end{tabular}

and together review the recommendations according to the Standard of Practice for Referral Consultation created by the College of Physicians \& Surgeons of Alberta. ${ }^{29}$ However, $49 \%$ of participants in this study did not know if their family doctor had obtained advice from a specialist to support their care. This reiterates the importance of involving patients and family caregivers in the care conversation, including communications between healthcare providers in the primary care-to-specialty care interface. ${ }^{6}$

In this study, a majority of patients and caregivers were comfortable with physicians seeking advice electronically via secure online messaging or over the phone.

Participants also rated email as the preferred method of communication to receive notifications about their referrals, followed by an online patient portal. This corroborated with other research findings that most patients seen at specialist centers had a high level of acceptance for communicating with their healthcare providers using modern communication technologies like websites, emails and mobile phones. ${ }^{30} \mathrm{~A}$ previous paediatric study found that parents aged 31-40 years were more likely to use email communication than other age groups ${ }^{31}$; however, there was no significant difference between age groups in regards to their expressed interest in using email in this study.

From patients' and caregivers' perspectives, security of transferred information, privacy and confidentiality of patient information, misunderstanding of communication,

Figure 1. Information that Participants Would Like to Receive Electronically

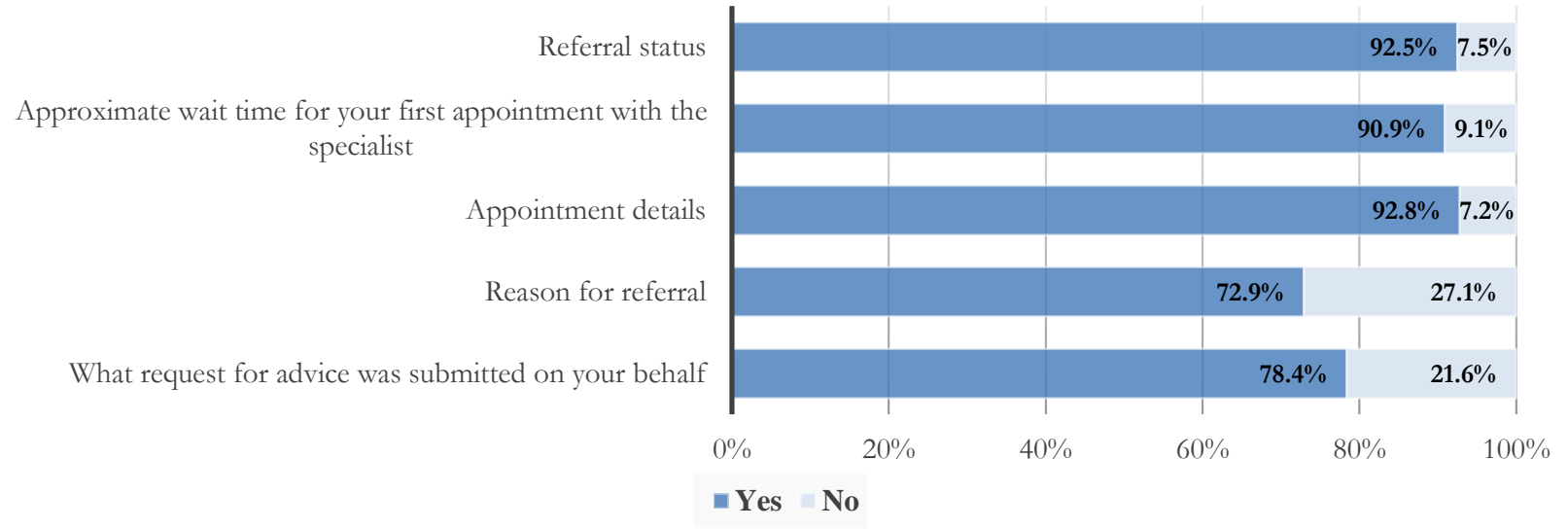


Figure 2. The Most Convenient Format of Electronic Notifications

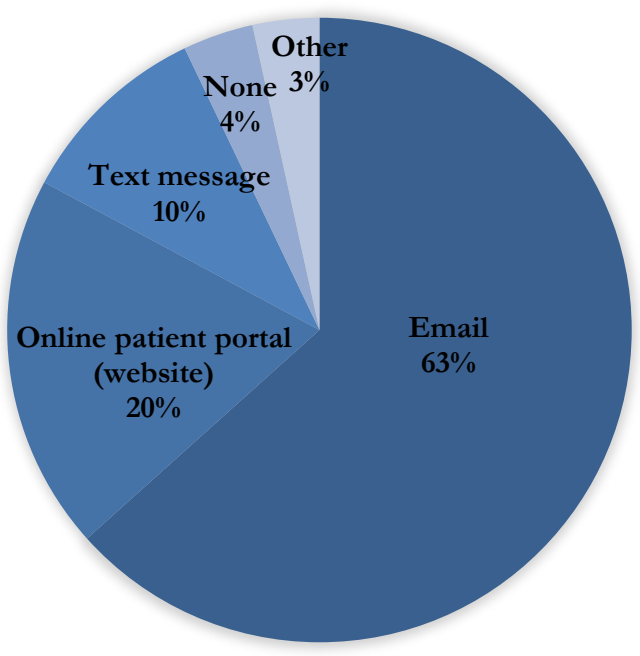

and time demands for communication electronically were their main concerns. Interestingly, participants in this study seemed to be more concerned about using mobile phone text messages than other communication modalities (i.e. secure online messages or phone calls). These concerns are similar to findings of other research studies on using modern communication technologies in healthcare settings, which included distraction, errors, depersonalized care, violation of privacy and confidentiality. ${ }^{27,32,33}$

There is no doubt about the benefits of using electronic advice - it can reduce wait times for patients to receive recommendations from specialists, decrease the number of unnecessary in-person specialist appointments, and increase primary care providers' confidence to manage patients' conditions in the community. ${ }^{16-20} \mathrm{It}$ is incumbent upon healthcare providers and policy makers to work together and find ways to optimize these benefits by spreading and scaling up electronic advice, while minimizing risks to patient care and privacy. First and foremost, strategies should be in place to address their concerns about security of transferred information, miscommunication and delayed responses. Increasing patients' and family caregivers' awareness of available nonurgent doctor-to-doctor advice services is a crucial next step to promote person-centered care in the referralconsultation process. Technology will change healthcare delivery and access to information but the patient voice and patient experience should guide future policy direction and leadership action. ${ }^{34}$

\section{Limitations}

There is an overrepresentation of women $(82 \%)$ due to the nature of voluntary and anonymous participation in the online survey. Considering the method of survey distribution, participants were recruited via social media and by email; thus our results may be skewed towards a higher level of acceptance for electronic advice and communication. Additionally, most participants had higher education with $64 \%$ of the sample population having graduated from college or university. This may also contribute to a higher level of acceptance for electronic communication technology without significant differences between age groups.

\section{Conclusion}

Communication is important during the referral and consultation process. We should not only consider healthcare providers' perspectives on referral-consultation communications, but also the perception and preference of patients and family caregivers on doctor-to-doctor advice and referral communications. This study found the majority of patients and caregivers had a high level of acceptance of physicians seeking non-urgent clinical advice from specialists electronically and over the phone, as well as their preferences to receive more communication related to their referrals by email or an online patient portal. This study also identified areas of concern and improvement for using electronic or phone technologies on virtual consultations amongst healthcare providers. Increasing patients' and family caregivers' awareness of doctor-to-doctor advice services is essential to promote person-centered care with enhanced patient involvement 
in Alberta. Findings in this study can help healthcare providers, policy makers and governments better evaluate and develop strategies to improve doctor-to-doctor advice and patient communications in the referral and consultation process.

\section{References}

1. Baxter SK, Blank L, Woods HB, Payne N, Rimmer M, Goyder E. Using logic model methods in systematic review synthesis: Describing complex pathways in referral management interventions. BMC Medical Research Methodology. 2014;14(1):62.

2. Blundell N, Clarke A, Mays N. Interpretations of referral appropriateness by senior health managers in five PCT areas in England: A qualitative investigation. Quality \& Safety in Health Care. 2010;19(3):182-186.

3. Barua B, Moir M. Waiting your turn: Wait time for health care in Canada, 2019 Report. https://www.fraserinstitute.org/sites/default/files/wai ting-your-turn-2019-rev17dec.pdf. Published December 10, 2019. Accessed March 26, 2020.

4. Schoen C, Osborn R, Doty MM, Squires D, Peugh J, Applebaum S. A survey of primary care physicians in eleven countries, 2009: Perspectives on care, costs, and experiences. Health Affairs. 2009;28(Suppl1):w1171w1183.

5. ConsultLoop. The ConsultLoop wait time report: Data shines its light.

http:/ /www.consultloop.com/consultloop-wait-timereport-data-shines-light/. Published November 20, 2018. Accessed March 16, 2020.

6. Wong A, Rizvi SK, Aremu A, Glassford J. Patients' and caregivers' views on communication in the referralconsultation process: A qualitative study. Healthcare Quarterly (Toronto, Ont). 2020;22(4):26-32.

7. Mehrotra A, Forrest CB, Lin CY. Dropping the baton: Specialty referrals in the United States. The Milbanke Quarterly. 2011;89(1):39-68.

8. Sampson R, Cooper J, Barbour R, Polson R, Wilson P. Patients' perspectives on the medical primarysecondary care interface: Systematic review and synthesis of qualitative research. BMJ Open. 2015;5(10):e008708.

9. Easley J, Miedema B, Carroll JC, et al. Coordination of cancer care between family physicians and cancer specialists: Importance of communication. Can Fam Physician. 2016;62(10):e608-e615.

10. Health Quality Council of Alberta. Patient perspectives on an electronic referral system for Alberta.

https://hqca.ca/wp-

content/uploads/2018/05/E_Referral_Summary_Rep ort_FINAL.pdf. Published January 2016. Accessed March 16, 2020.

11. Luu NP, Pitts S, Petty B, et al. Provider-to-provider communication during transitions of care from outpatient to acute care: A systematic review. J Gen Intern Med. 2016;31(4):417-425.

12. Singh H, Esquivel A, Sittig DF, et al. Follow-up actions on electronic referral communication in a multispecialty outpatient setting. J Gen Intern Med. 2011;26(1):64-69.

13. Gandhi TK, Sittig DF, Franklin M, Sussman AJ, Fairchild DG, W. D. Communication breakdown in the outpatient referral process. J Gen Intern Med. 2000;15(9).

14. Greenwood-Lee J, Jewett L, Woodhouse L, Marshall DA. A categorisation of problems and solutions to improve patient referrals from primary to specialty care. BMC Health Serv Res. 2018;18(1):986.

15. Alberta Health. Report and recommendations blue ribbon panel on Alberta's finances.

https://open.alberta.ca/publications/report-andrecommendations-blue-ribbon-panel-on-alberta-sfinances. Published August 2019. Accessed March 16, 2020.

16. Keely E, Traczyk L, Liddy C. Patients' perspectives on wait times and the referral-consultation process while attending a tertiary diabetes and endocrinology centre: Is econsultation an acceptable option? Canadian Journal of Diabetes. 2015;39(4):325-329.

17. Gilani S, Bommakanti K, Friedman L. Electronic consults in otolaryngology: A pilot study to evaluate the use, content, and outcomes in an academic health system. The Annals of Otology, Rhinology, and Laryngology. 2019:3489419882726.

18. Vimalananda VG, Meterko M, Waring ME, et al. Tools to improve referrals from primary care to specialty care. The American Journal of Managed Care. 2019;25(8):e237-e242.

19. Nabelsi V, Lévesque-Chouinard A, Liddy C, Dumas Pilon M. Improving the referral process, timeliness, effectiveness, and equity of access to specialist medical services through electronic consultation: Pilot study. JMIR Med Inform. 2019;7(3):e13354-e13354.

20. Alberta Health Services. Alberta Netcare eReferral evaluation report: August 2018 to October 2019. https://www.albertanetcare.ca/documents/NetcareeReferral-Evaluation-Report_2019.pdf. Published November 2019. Accessed March 2, 2020.

21. de Man G, Moroz I, Mercer J, Keely E, Liddy C. Primary care clinician adherence to specialist advice in electronic consultation. Annals of Family Medicine. 2019;17(2):150-157.

22. Bello AK, Zaidi D, Braam B, et al. Electronic advice request system for nephrology in Alberta: Pilot results and implementation. Canadian Journal of Kidney Health and Disease. 2019;6:2054358119879778.

23. Keely E, Li J, Magner P, Afkham A, Liddy C. Nephrology eConsults for primary care providers: Original investigation. Canadian Journal of Kidney Health and Disease. 2018;5:20543581177536192054358117753619. 
24. Vimalananda VG, Orlander JD, Afable MK, et al. Electronic consultations (E-consults) and their outcomes: A systematic review. J Am Med Inform Assoc. 2020;27(3):471-479.

25. Liddy C, Drosinis P, Fogel A, Keely E. Prevention of delayed referrals through the Champlain BASE

eConsult service. Can Fam Physician. 2017;63(8):e381e386.

26. Liddy C, Drosinis P, Keely E. Electronic consultation systems: Worldwide prevalence and their impact on patient care-a systematic review. Family Practice. 2016;33(3):274-285.

27. Dendere R, Slade C, Burton-Jones A, Sullivan C, Staib A, Janda M. Patient portals facilitating engagement with inpatient electronic medical records: A systematic review. Journal of Medical Internet Research. 2019;21(4):e12779.

28. Brand PL, Stiggelbout AM. Effective follow-up consultations: The importance of patient-centered communication and shared decision making. Paediatric Respiratory Reviews. 2013;14(4):224-228.

29. College of Physicians \& Surgeons of Alberta. Advice to the profession - Referral consultation.

http://www.cpsa.ca/wpcontent/uploads/2017/01/AP_ReferralConsultation.pdf. Published January 2017. Accessed March 2, 2020.

30. Haase R, Schultheiss T, Kempcke R, Thomas K, Ziemssen T. Use and acceptance of electronic communication by patients with multiple sclerosis: A multicenter questionnaire study. Journal of Medical Internet Research. 2012;14(5):e135.

31. Kleiner KD, Akers R, Burke BL, Werner EJ. Parent and physician attitudes regarding electronic communication in pediatric practices. Pediatrics. 2002;109(5):740-744.

32. Broussard BS, Broussard AB. Using electronic communication safely in health care settings. Nursing for Women's Health. 2013;17(1):59-62.

33. Bromwich M, Bromwich R. Privacy risks when using mobile devices in health care. Cmaj. 2016;188(12):855856.

34. Wolf JA. The future of patient experience: Five thoughts on where we must go from here. Patient Experience Journal. 2019;6(3):1-4 


\section{Appendix}

\section{Survey for Patients and Family Caregivers: Specialty Advice and Referral}

Background: Alberta Health Services' Access Improvement team works together with various healthcare professional bodies to improve patient access to scheduled specialty services. One of our top priorities is to improve the quality of communication between patients, referring doctors and consulting healthcare providers.

Purpose of this survey: To study patients' and family caregivers' degree of satisfaction with the referral process and perspectives on receiving communication electronically.

Target Audience: Patients or family caregivers who have been referred to see specialists or other specialized health services in Alberta and other Canadian Provinces and Territories.

What is a referral? A referral is a request from one doctor/practitioner to another to seek an opinion or treatment that the referring provider cannot fulfill themselves.

Participation: Your participation is voluntary and all collected information is anonymous. Your input is important and will support the Access Improvement team to develop strategies that improve the quality of communication in the referral and consultation process.

If you have questions about this survey, please contact the AHS Access Improvement team at access.eReferral@ahs.ca.

* indicates mandatory questions.

Q1: Do you give consent to participate this survey?*

$\square$ Yes $\square$ No

Note: If "No" is selected, survey ends.

Q2: In what capacity have you experienced the referral system in Canada? (Check all that apply)*

$\square$ Myself as a patient

$\square$ Family member or friend whom I provide care

$\square$ I don't have any direct/indirect referral experience

Note: If "I don't have any direct/indirect referral experience" is selected, survey ends.

Q3: When was the last time that you or someone you provide care for was referred to a specialist?*

$\square$ Less than 1 year ago

$\square 1-4$ years ago

$\square 5$ years ago or longer

In the following questions, "you" refers to you as a patient and/or someone you provide care for.

Q4: From your experience, how satisfied were you with the referral process?*

(Definition: Referral process starts from the moment when your family doctor sent you to see a specialist; referral process ends when your specialist sent you back to family doctor after in-person appointments or treatments.)

$\square$ Satisfied $\square$ Neutral $\square$ Dissatisfied

Note: If "Dissatisfied" is selected, proceed to Q4a; otherwise proceed to Q5.

Q4a: Please briefly explain why you were not satisfied: 
Q5: From your experience, how satisfied were you with the following parts of referral process?*

\begin{tabular}{|c|c|c|c|c|}
\hline & Satisfied & Neutral & Dissatisfied & Not Available \\
\hline $\begin{array}{l}\text { a. Getting a referral from family doctor or primary care } \\
\text { provider }\end{array}$ & $\square$ & $\square$ & $\square$ & $\square$ \\
\hline $\begin{array}{l}\text { b. Wait time between referral made and specialist } \\
\text { appointment date }\end{array}$ & $\square$ & $\square$ & $\square$ & $\square$ \\
\hline c. Options for specialist appointment times & $\square$ & $\square$ & $\square$ & $\square$ \\
\hline d. Options to see a specialist in a particular location & $\square$ & $\square$ & $\square$ & $\square$ \\
\hline $\begin{array}{l}\text { e. Instructions for your appointment (e.g., Directions, } \\
\text { parking, what to bring with you) }\end{array}$ & $\square$ & $\square$ & $\square$ & $\square$ \\
\hline $\begin{array}{l}\text { f. Getting diagnostic tests done prior to specialist } \\
\text { appointment (e.g.,. Blood work, x-ray, ultrasound) }\end{array}$ & $\square$ & $\square$ & $\square$ & $\square$ \\
\hline $\begin{array}{l}\text { g. Communication between your family doctor and } \\
\text { specialist about your health conditions and care plan }\end{array}$ & $\square$ & $\square$ & $\square$ & $\square$ \\
\hline h. Follow-up appointment with your family doctor & $\square$ & $\square$ & $\square$ & $\square$ \\
\hline
\end{tabular}

Q6: Prior to your first appointment with the specialist, did you receive the following information?*

\begin{tabular}{lccc}
\hline & Always & Sometimes & No \\
\hline $\begin{array}{l}\text { a. Reason for referral (i.e., Why you were sent to see a } \\
\text { specialist) }\end{array}$ & $\square$ & $\square$ & $\square$ \\
\hline $\begin{array}{l}\text { b. Anticipated referral wait time } \\
\text { c. Referral status (i.e., If your referral was accepted, waitlisted }\end{array}$ & $\square$ & $\square$ & $\square$ \\
or declined) & $\square$ & $\square$ & $\square$ \\
\hline $\begin{array}{l}\text { d. Appointment details (i.e., Date, time and address) } \\
\text { e. Specialist's name }\end{array}$ & $\square$ & $\square$ & $\square$ \\
$\begin{array}{l}\text { f. Preparation work before an appointment (e.g,. Fasting, lab } \\
\text { work) }\end{array}$ & $\square$ & $\square$ & $\square$ \\
\hline $\begin{array}{l}\text { g. Instructions for your appointment (e.g., Directions, parking, } \\
\text { what to bring with you) }\end{array}$ & $\square$ & $\square$ & $\square$ \\
\hline
\end{tabular}

\section{Q7: Did you play a role in tracking your referral?*}

\begin{tabular}{lcccc} 
& Always & Sometimes & No & Not Sure \\
\hline a. Contact your family doctor about your referral & $\square$ & $\square$ & $\square$ & $\square$ \\
\hline b. Contact the specialist's office about your referral & $\square$ & $\square$ & $\square$ & $\square$ \\
\hline c. Take notes about your referral & $\square$ & $\square$ & $\square$ & $\square$ \\
\hline d. Take notes about recommendations from the specialist & $\square$ & $\square$ & $\square$
\end{tabular}

Q8: In Alberta and other provinces, family doctors can obtain advice from specialists for non-urgent questions via methods which do not involve a patient physically seeing a specialist (via telephone, electronically). Has your family doctor ever obtained advice from a specialist to support your care via any of these methods? $*$

$$
\begin{aligned}
& \square \text { Yes } \square \text { No } \square \text { I don't know } \\
& \text { Note: If "Yes" is selected, proceed to Q9; otherwise proceed to Q12. }
\end{aligned}
$$

Q9: By what method(s) did your family doctor obtain the advice? (Check all that apply)*

$\square$ Online conversation $\square$ Phone conversation $\square$ Text Message $\square$ I don't know

Q10: In the course of these advice requests, did your family doctor ask if you had any questions for the specialist?*

$\square$ Always $\square$ Sometimes $\square$ No

Q11: Did your family doctor review with you the recommendations given by the specialist? *

$\square$ Always $\square$ Sometimes $\square$ No

\section{Perspectives on Electronic Advice and Notification}

Q12: Would you be comfortable having your family doctor seek advice from a specialist electronically (i.e. secure online messaging) to support your care? * 
$\square$ Yes $\square$ No $\square$ I don't know

Note: If "Yes" is selected, proceed to Q13; otherwise, proceed to Q12a.

Q12a: What concerns might you have about obtaining specialist advice this way?

Q13: Would you be comfortable having your family doctor seek advice from a specialist over the phone (including via text message) to support your care?*

$\square$ Yes $\square$ No $\square$ I don't know

Note: If "Yes" is selected, proceed to Q14; otherwise, proceed to Q13a.

Q13a: What concerns might you have about obtaining specialist advice this way?

Q14: Would you be comfortable having your family doctor seek advice from a specialist without sending you to see the specialist in person?*

$\square$ Yes $\square$ No $\square$ I don't know

Note: If "Yes" is selected, proceed to Q15; otherwise, proceed to Q14a.

Q14a: What are your concerns?

Alberta is exploring the option of electronic notifications (i.e. secured messaging) to patients/ their caregivers in order to assist the referral communication process.

Q15: Please indicate what information related to your referral you would like to receive electronically: (Check all that apply)*

$\square$ Referral status (i.e. If your referral was received, accepted, waitlisted or declined)

Approximate wait time for your first appointment with the specialist

$\square$ Appointment details (Specialist's name, date, time and location)

$\square$ Reason for referral

$\square$ What advice request was submitted on your behalf (i.e. If your doctor sends an electronic secured message to the specialist seeking advice to manage your condition rather than requesting an in-person appointment for you)

$\square$ None - I don't want to receive any notifications electronically

$\square$ Other, please specify:

Q16: Which format of electronic messaging would be most convenient with you?*

Email

Online patient portal (website)

$\square$ Text message 
None - I don't want to receive any notifications electronically

$\square$ Other, please specify:

Demographic Questions

Q17: Your Age:*
$\square$ Under 20 years old
$\square$ 20-29 years old
$\square$ 30-39 years old
$\square$ 40-49 years old
$\square$ 50-59 years old
$\square$ 60-69 years old
$\square 70-79$ years old
$\square 80$ years or older

Q18: Your Gender:*

$\square$ Female

$\square$ Male

$\square$ Prefer not to say

$\square$ Prefer to self-describe:

Q19: Your Address: In which province or territories do you live?*
$\square$ Alberta
$\square$ British Columbia
$\square$ Manitoba
$\square$ New Brunswick
$\square$ Newfoundland and Labrador
$\square$ Northwest Territories
$\square$ Nova Scotia
$\square$ Nunavut
$\square$ Ontario
$\square$ Prince Edward Island
$\square$ Quebec
$\square$ Saskatchewan
$\square$ Yukon

Q20: Your Education: What is the highest level of education you have completed? *

$\square$ Did not attend school

$\square$ Elementary school (1st - 6th grade)

$\square$ Some high school (7th -12 th grade)

$\square$ Graduated from high school

$\square$ Some college / university

$\square$ Graduated from college / university

$\square$ Bachelor's degree

$\square$ Master's degree

$\square$ Doctorate degree

Q21: Employment Status: Are you currently working? *

$\square$ Yes, full-time $\quad \square$ Yes, part-time $\quad \square$ No, retired $\quad \square$ No, unable to work

$\square$ Other, please specify: 